\title{
Correction to: Environ. Eng. Sci. 2017;34(1):51-61. DOI: 10.1089/ees.2016.0223
}

N THE JANuARy 2017 IsSUE of Environmental Engineering Science (vol. 34, no. 1, pp. 51-61, DOI: 10.1089/ees.2016.0223), in the article entitled "Academic Research in the 21st Century: Maintaining Scientific Integrity in a Climate of Perverse Incentives and Hypercompetition" by Marc A. Edwards and Siddhartha Roy, an error has been discovered on page 55, second column, under the section heading The high costs of research misconduct.

The statement reading "Indeed, delving deeper, $34 \%$ of researchers self-reported that they have engaged in "questionable research practices," including "dropping data points on a gut feeling" and "changing the design, methodology, and results of a study in response to pressures from a funding source," whereas $72 \%$ of those surveyed knew of colleagues who had done so (Fanelli, 2009)." should have been written as, "Indeed, delving deeper, up to $34 \%$ of researchers self-reported that they have engaged in "questionable research practices," including "dropping data points on a gut feeling" and "changing the design, methodology, and results of a study in response to pressures from a funding source," whereas up to $72 \%$ of those surveyed knew of colleagues who had done so (Fanelli, 2009)."

The online version of the article has been corrected to reflect this change.

The authors wish to apologize for the error. 